\title{
Is the string test a useful alternative to gastroscopy with biopsy for H. pylori identification?
}

\author{
A. J. del Pozo García and J. P. Gisbert ${ }^{1}$ \\ Services of Digestive Diseases. Hospital Universitario de Guadalajara and ${ }^{1}$ Hospital Universitario de La Princesa. \\ Madrid. Spain
}

Del Pozo García AJ, Gisbert JP. Is the string test a useful alternative to gastroscopy with biopsy for $H$. pylori identification? Rev Esp Enferm Dig 2006; 98: 542-549.

\section{INTRODUCTION}

The diagnosis of Helicobacter pylori (H. pylori) infection may be reached using a number of both "direct" and "indirect" methods (1). The former rely on the "direct" identification of this organism via the histologic and microbiologic study of samples obtained with gastric biopsy. Therefore, they require endoscopy, which is certainly inconvenient for patients. This inconvenience and the relatively high cost of endoscopy has prompted the search for simpler alternatives, particularly in developing countries (2). "Indirect" methods are based upon the study and detection of selected bacterial characteristics, including the organism's ability to hydrolyze urea -property underlying the ${ }^{13} \mathrm{C}$-urea breath test (1)- and the host's immune system response to infection (detection of specific antibodies using serologic tests). As a result, these "non-invasive" techniques add to their diagnostic accuracy the benefits of lower aggression and better tolerability by patients, but also the drawback that virulence or strain resistance patterns cannot be studied.

Thus far, when aiming at $H$. pylori collection for the performance of more or less complex techniques such as microscopy, culture, DNA analysis, cytotoxin screening, strain differentiation, or antimicrobial susceptibility

Recibido: 18-01-06.

Aceptado: 07-02-06.

Correspondencia: Javier P. Gisbert. Playa de Mojácar, 29. Urb. Bonanza. 28669 Boadilla del Monte. Madrid. Fax: 913093 911. e-mail: gisbert@meditex.es analyses, endoscopy with gastric biopsy sampling was mandatory. The alarming, progressive increase of bacterial resistance rates has led to an increasing number of failed eradication procedures -approximately $20 \%$ of therapy-nä̈ve individuals (3). Such lost efficacy makes sometimes advisable the collection of samples for culture, so that an antibiogram may be performed, and a more effective therapy is initiated according to bacterial susceptibility. Regarding this, there is some consensus on the performance of $H$. pylori cultures following a second failed eradication (4), while some authors have recommended this even prior to the index therapy, based on this strategy's higher cost-benefit ratio (5).

As resistance rates keep increasing, there is a growing need for a pre-treatment routine susceptibility test -as little aggressive as possible and efficient enough for $H$. pylori detection. The enterotest or string test is a method including the ingestion of a capsule attached to a long string, which is then extracted and analyzed for gastric secretions. This review attempts to assess the role of the string test in the diagnosis of $H$. pylori infection.

\section{DESCRIBING THE TECHNIQUE}

The enterotest or string test is a technique that was designed decades ago to collect fluids from the upper small bowel through the stomach, and was thus particularly used in the pediatric setting to obtain trophozoites in the study of giardiasis and other parasitoses. In 1995, some authors $(6,7)$ started using this test for $H$. pylori cultures. In this test, a fasting patient ingests a small $(7 \mathrm{~mm})$ gelatin capsule attached to a $90-140 \mathrm{~cm}$ long nylon string with a highly absorbent $60 \mathrm{~cm}$ long distal segment; the string is placed within the capsule, and unwinds during ingestion. Upon reaching the stomach, the gelatin capsule dissolves and the string absorbs gastric secretions (approximately $0.5 \mathrm{ml}$ per $10 \mathrm{~cm}$ ) (8). 
After a 30-180 minutes' interval, during which the patient may only take water and must remain in relative rest, the gastric juice-impregnated string is pulled out the mouth. This extraction must avoid contact between the string and the tongue and teeth; the string must then be pulled in a sustained, gentle manner, rather than in steps, with the patient keeping his or her mouth open during the process. To avoid sample contamination, mouthwahes using antiseptic solutions are recommended before extraction, as well as a careful, sterile manipulation of the string $(8,9)$. In a recent study by Marshall et al., patients using chlorhexidine washes before extraction improved culture efficacy rates for $H$. pylori from 39 to $75 \%$ (9). Once out of the body, the string is proximally cut and the initial $30-\mathrm{cm}$ segment is discarded, as it is non-absorbent and usually appears contaminated by nasopharyngeal flora.

No definite protocol has been developed yet for sample processing, but it is long known that $H$. pylori may survive below $10{ }^{\circ} \mathrm{C}$ beyond $48 \mathrm{~h}$ prior to culture, and that greater success rates are reported for such cultures when air exposure is minimized during sample processing, handling, and transportation (10). The procedure described by Samuels et al. may be used, in view of its thoroughness and good results (11). Using this method, the remaining string is submerged in a sterile tube with 5-10 $\mathrm{ml}$ of isotonic saline for one minute, which reduces bacterial colonization at the expense of a decrease in the number of $H$. pylori colonies. The sample is stored at $-70^{\circ} \mathrm{C}$ until processing, when it will be defrosted in $10 \mathrm{ml}$ of saline, plus centrifugation at $3,000 \mathrm{~g}$ for $10 \mathrm{~min}$. The supernatant is discarded, and the capsule is again suspended in $0.5 \mathrm{ml}$ of saline, and employed for culture and/or polymerase chain reaction (PCR).
The string test is usually well tolerated, but mild oropharyngeal discomfort (cough, sore throat) may occur during or after the procedure, and nausea is not uncommon during extraction. In one study, $73 \%$ of patients reported that an enterotest was preferable to gastroscopy (12).

\section{ENTEROTEST RELIABILITY IN THE DIAGNOSIS OF H. PYLORI INFECTION}

According to studies published so far, the sensitivity of the enterotest for the detection of $\mathrm{H}$. pylori oscillates between 37 and 97\%, but varies a lot (widely) depending on the performance and processing technique $(6,8,9,11-20)$ (Table I), as well as on the different string tests commercially available. Culture specificity from samples obtained using the enterotest reaches $100 \%$. The low sensitivity reported by some authors has been attributed to various variables such as: a) bacterial overgrowth from the flora; b) failed collection of enough organism colonies using the string; or c) organism death during handling and processing (19). In order to attempt and prevent bacterial overgrowth from the oral and nasal pharyngeal flora, $H$. pylori-specific culture media $(9,11)$ must be used, in addition to the above-mentioned extraction technique.

\section{ENTEROTEST AND CULTURE}

The first study to compare the effectiveness of $H$. pylori cultures between the enterotest and antral biopsy was reported by Pérez-Trallero et al. in 1995 (6). Both tech-

Table I. Diagnostic efficacy of the string test in studies reported so far

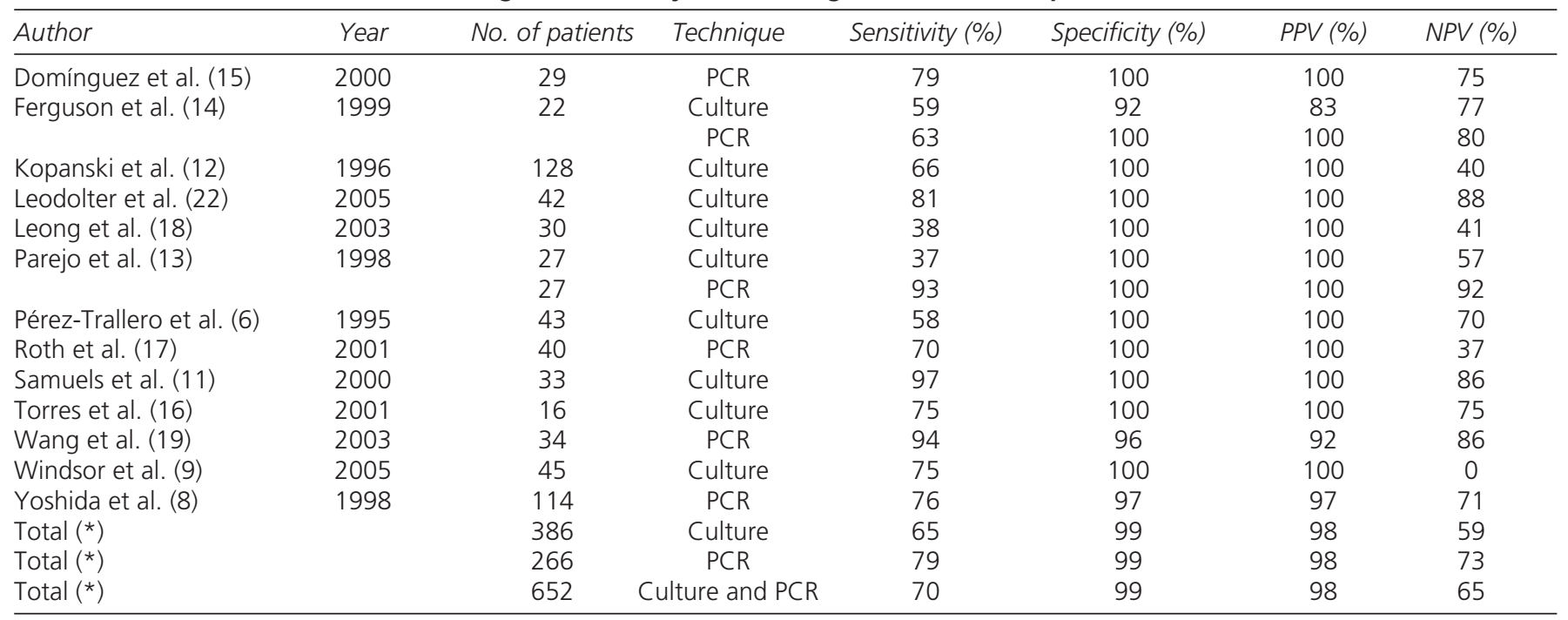

PPV: positive predictive value; NPV: negative predictive value; PCR: polymerase chain reaction; $\left({ }^{*}\right)$ : weighted mean value. 
niques were simultaneously compared in 36 adult patients with clinically suspected peptic ulcer or chronic gastritis. Samples obtained using both techniques were cultured on Brucella agar supplemented by $7 \%$ equine hemolyzed blood, and 1\% Vitox (Oxoid) specific for vancomycin $(15 \mu \mathrm{g} / \mathrm{mL})$ and trimethoprim $(5 \mu \mathrm{g} / \mathrm{mL})$, as well as in this same medium in the absence of antibiotics. Plates were incubated at $37{ }^{\circ} \mathrm{C}$ under microaerophilic conditions with $5 \%$ oxygen, $7 \%$ carbon dioxide, $2 \%$ hydrogen, and $86 \%$ nitrogen, and $80 \%$ humidity for 7 days. Cultures were deemed positive if colonies developed with a typical $H$. pylori morphology and positive oxidase, catalase, and urease activity following staining with acridine orange. Results showed a higher sensitivity in the group where gastric samples were obtained by biopsy, and consistency between both tests was moderate (21). Enterotest cultures showed a greater growth of flora other than $H$. pylori when compared to biopsy. The addition of $10 \mu \mathrm{g} / \mathrm{mL}$ of nalidixic acid to selective media increased sensitivity in the enterotest group. Since this report, the diagnostic efficacy of enterotest has been assessed in various $H$. pylori-selective culture media, and results have been thus inconsistent. Upon a review of the literature, we estimated that the mean sensitivity of enterotest-related samples is $65 \%$ (Table I), which is rather poor when compared to that of standard diagnostic methods. However, the study by Amy Samuels et al. (11) obtained a high sensitivity $-97 \%$ - as a result of careful methodology and the use of three selective culture media: WilkinsChalgren agar with Dent (Oxoid) supplementation, colistin-nalidixic agar with Dent supplementation, and Skirrow agar.

\section{ENTEROTEST AND PCR}

The previous demonstration that the use of PCR for gastric biopsy -based upon restriction fragment length polymorphism (RFLP) - may serve to characterize and identify $H$. pylori strains infecting the stomach (22) has led to the application of this technique on enterotest-collected samples. The use of PCR in the string test considerably improves sensitivity by the sequencing of $H$. pylori-specific DNA $(12,14-16,18,23)$, and has increased it in a recent study from $37 \%$ when based on cultures exclusively to $93 \%$ when PCR was added (13). Thus, following our review of the literature we estimated that the mean sensitivity of PCR on enterotest-collected samples for the identification of $H$. pylori is $79 \%$, and increases by $14 \%$ culture sensitivity. As an added benefit, PCR allows to tell recrudescence apart from true reinfection following $H$. pylori eradication by comparing extant strains before and after therapy $(23,24)$.

The major drawback of PCR is that it cannot be performed in all hospitals, since this technique requires sophisticated equipments and experienced personnel; furthermore, its use greatly increases costs. On the other hand, PCR -in contrast with culture- does not allow the performance of microbial susceptibility studies (19).

On the contrary, the fact that PCR may characterize the various $H$. pylori strains may help measure the differing virulences of these strains, and evaluate the potential mechanisms of infection transmission.

\section{ENTEROTEST INDICATIONS}

The availability of an "indirect" test for $H$. pylori diagnosis such as the ${ }^{13} \mathrm{C}$ urea breath test, which is fast, almost devoid of adverse effects, well tolerated, and relatively affordable $(25,26)$, would restrict the string test to just a few indications. Thus, in yet undiagnosed patients, it seems advisable that a breath test be previously performed to confirm the presence of $H$. pylori, and that the string test be reserved for cases with confirmed infection (12). However, under what circumstances would this be useful? The string test may play a role in a number of clinical situations: a) after a failed eradication therapy course with culture and antibiogram purposes, so that appropriate antibiotics may be rationally selected and gastroscopy is spared (7); b) when a PCR is needed whatever the cause, without recourse to gastroscopy; and c) in population-based epidemiologic studies, to determine the prevalence of infection in healthy individuals for populations lacking breath-test technology in a minimally invasive manner, even if serology is a simpler option in such cases.

As previously seen, there is some consensus in indicating a culture and antibiogram after two failed $H$. pylori eradication treatments (4). Thus far, under such circumstances, patients underwent a new gastroscopy and gastric biopsy for sample culturing. The string test may be an alternative to gastroscopy in view of its scarce aggressiveness and better tolerability, especially in patients unwilling to undergo endoscopy or with a high risk for complications arising from their previous situation: altered anatomy (Zenker's diverticulum) or associated comorbidity (anticoagulating therapy, hemorrhagic diathesis, severe cardiorespiratory disturbances, immunodeficiency). A recent study (22) compared the efficacy of $H$. pylori cultures and the analysis of bacterial susceptibility to clarithromycin and metronidazole in patients with failed eradication -documented with a breath test- between samples obtained with the string test and samples collected by endoscopic biopsy, and found little differences in favor of biopsy; the authors concluded that using a string test under such circumstances may reduce the number of endoscopies by up to $80 \%$, with considerable economic savings.

The role of the string test in directly documenting eradication success remains to be assessed, but breath testing has obvious advantages -lack of adverse effects, easy to perform, acceptable costs after initial investment (mass spectrometer). Anyway, should the sensitivity of the string test be optimized in the absence of PCR, the 
role of this test would surely have greater preponderance.

The "test and treat" strategy (diagnosing and treating $H$. pylori infection) relies on the early use of an indirect test (serology or breath test) (27). There are increasingly more arguments -based both on decision analysis models and prospective studies- supporting the use of such a strategy, as it is associated with a reduced number of endoscopies and considerable savings (27). Hence, the II Spanish Consensus Conference on H. pylori infection (28) has recently supported the "test and treat" strategy as a valid alternative for younger patients with dyspepsia and no "alarm" signs. The role of the string test as an early component of this strategy may be approached. Some authors $(29,30)$ advocate for a fast urease test (CLOtest) on enterotest-collected samples rather than a previous breath test for the study of only positive samples, which would reduce costs. However, the latter alternative has the limitation of potential false positive results due to the presence of contaminating flora from the upper respiratory tract $(30,31)$.

\section{CONCLUSIONS}

To summarize, the string test is a minimally invasive technique that has been used for $H$. pylori identification during the past few years, and that may play a role in the diagnosis of this infection because of its user-friendliness (it may be used in both pediatric and elderly patients), harmlessness, good acceptance by patients, and reduced costs (provided no PCR is associated). However, thus far, and pending definitive validation, its use should be restricted to research studies. A potential indication may be antimicrobial-oriented culturing from enterotest-collected samples in patients with breath test-documented eradication failure, and in cases where gastroscopy is better avoided. Finally, the recently reported higher sensitivity rates in enterotest-related cultures, together with an increasingly simplified processing of samples and reduced PCR costs, may extend the future role of the string test in the diagnosis of $H$. pylori infection.

\section{ACKNOWLEDGEMENTS}

This review was partly supported by a grant from Instituto de Salud Carlos III (C03/02).

\section{REFERENCES}

1. Gisbert JP. Diagnóstico de la infección por Helicobacter pylori. Rev Clin Esp 2000; 200: 370-2.

2. Westbloom TU, Bhatt BD. Diagnosis of Helicobacter pylori infection. Curr Top in Microbiol and Immunol 1999; 241: 215-35.

3. Gisbert JP, Pajares JM. Review article: Helicobacter pylori "rescue" regimen when proton pump inhibitor-based triple therapies fail. Aliment Pharmacol Ther 2002; 16: 1047-57.
4. Malfertheiner P, Megraud F, O'Morain C, Hungin AP, Jones R, Axon A, et European Helicobacter Pylori Study Group (EHPSG). Current concepts in the management of Helicobacter pylori infection-the Maastricht 2-2000 Consensus Report. Aliment Pharmacol Ther 2002; 16 : 167-80.

5. Breuer T, Graham DY. Costs of diagnosis and treatment of Helicobacter pylori infection: when does choosing the treatment regimen based susceptibility testing become cost effective? Am J Gastroenterol 1999; 94: 725-9.

6. Pérez-Trallero E, Montes M, Alcorta M, Zubillaga P, Tellería E. Nonendoscopic method to obtain Helicobacter pylori for culture. Lancet 1995; 345: 622-3.

7. Pérez-Trallero E, Montes M, Larranaga M, Arenas JI. How long for the routine Helicobacter pylori antimicrobial susceptibility testing? The usefulness of the string test to obtain Helicobacter for culture. Am J Gastroenterol 1999; 94: 725-9.

8. Yoshida H, Hirota K, Shiratori Y, Nihei T, Amano S, Yoshida A, et al. Use of gastric juice-based PCR assay to detect Helicobacter pylori infection in culture-negative patients. J Clin Microbiol 1998; 36: 317 30.

9. Windsor HM, Abioye-Kuteyi EA, Marshall BJ. Methodology and transport medium for collection of Helicobacter pylori on a string test in remote locations. Helicobacter 2005; 10: 630-4.

10. Solstesz V, Zeeber B, Wadstrom T. Optimal survival of Helicobacter pylori under various transport conditions. J Clin Microbiol 1992; 30: $1453-6$.

11. Samuels AL, Windsor H, Ho GY, Goodwin LD, Marshall BJ. Culture of Helicobacter pylori from a gastric string may be an alternative to endoscopic biopsy. J Clin Microbiol 2000: 2438-9.

12. Kopanski Z, Schlegel-Zawadzka M, Witkowska B, Cienciala A, Szczerba J. Role of enterotest in the diagnosis of the Helicobacter pylori infections. Eur J Med Res 1996; 1: 520-2.

13. Parejo R, García Arata I, de Rafael L, Cantón R, Olivares F, Boixeda $\mathrm{D}$, et al. Usefulness of the enterotest method for the diagnosis of Helicobacter pylori infection in children. Gut 1998; 43 (Supl. 2): A74.

14. Ferguson DA Jr, Jiang C, Chi D, Laffan JJ, Li C, Thomas E. Evaluation of two string tests for obtaining gastric juice for culture, nested PCR detection, and combined single -and double- stranded conformational polymorphism discrimination of Helicobacter pylori. Dig Dis Sci 1999; 44: 2056-62.

15. Domínguez-Bello MG, Cienfuentes C, Romero R, García P, Gómez I, Mago V, et al. PCR detection of Helicobacter pylori in string-absorbed gastric juice. FEMS Microbiol Lett 2001; 198: 15-6.

16. Torres J, Camorlinga M, Pérez-Pérez G, González G, Muñoz O. Validation of the string test for the recovery of Helicobacter pylori from gastric secretions and correlation of its results with urea breath test results, serology, and gastric pH levels. J Clin Microbiol 2001; 39: $1650-1$.

17. Roth DE, Velapatino B, Gilman RH, Su WW, Berg DE, Cabrera L, et al. A comparison of a string test-PCR assay and a stool antigen immunoassay (HpSA) for Helicobacter pylori screening in Peru. Trans R Soc Trop Med Hyg 2001; 95: 398-9.

18. Leong RW, Lee CC, Ling TK, Leung WK, Sung JJ. Evaluation of the string test for the detection of Helicobacter pylori. World J Gastroenterol 2003; 9: 309-11.

19. Wang SW, Yu FJ, Lo YC, Yang YC, Wu MT, Wu IC, et al. The clinical utility of string-PCR test in diagnosing Helicobacter pylori infection. Hepatogastroenterology 2003; 50: 1208-13.

20. Leodolter A, Wolle K, von Arnim U, Kahl S, Treiber G, Ebert MP, et al. Breath and string test: a diagnostic package for identification of treatment failure and antibiotic resistance of Helicobacter pylori without the necessity of upper gastrointestinal endoscopy. World J Gastroenterol 2005; 11: 584-6.

21. Patchett SE, Mulcahy HE, Farthing MJ. String test for Helicobacter pylori. Lancet $1995 ; 345: 1580-1$.

22. Li C, Ha T, ChiDS, Ferguson DA, Jiang C, Laffan J, Thomas E. Differentiation of Helicobacter pylori strains directly from gastric biopsy specimens by PCR-based restriction fragment length polymorphism analysis without culture. J Clin Microbiol 1997; 35: 3023-5.

23. Bell GD, Powell KU, Burridge SM, Harrison G, Rameh B, Weil J, et al. Recurrence or recrudescence after apparently successful eradication of Helicobacter pylori infection: implications for treatment of patients with duodenal ulcer disease. QJM 1993; 86: 375-82. 
24. Gisbert JP, García Arata I, Boixeda D, Barba M, Cantón R, García Plaza A, et al. Role of partner's infection in reinfection after Helicobacter pylori eradication. Eur J Gastroenterol Hepatol 2002; 14: 86571.

25. Gisbert JP, Ducons J, Gomollón F, Domínguez-Muñoz JE, Borda F, Miño G, et al. Validación de la prueba del aliento con 13-C urea para el diagnóstico inicial de la infección por Helicobacter pylori y la confirmación de su erradicación tras el tratamiento. Rev Esp Enferm Dig 2003; 95: 121-6, 115-20.

26. Gisbert JP, Pajares JM. Review article: C-urea breath test in the diagnosis of Helicobacter pylori infection- a critical review. Aliment Pharmacol Ther 2004; 20: 1001-17.

27. Gisbert JP, Pajares JM. Helicobacter pylori "test-and-treat" strategy for dyspeptic patients. Scand J Gastroenterol 1999; 34: 64452.
28. Monés J, Gisbert JP, Borda F, Domínguez-Muñoz E; Grupo Conferencia Española de Consenso Sobre Helicobacter Pylori. Indicaciones, métodos diagnósticos y tratamiento erradicador de Helicobacter pylori. Recomendaciones de la II Conferencia Española de Consenso. Rev Esp Enferm Dig 2005; 97: 348-74.

29. Fedalei AG, Parker AL, Kadakia SC, Enghardt MH. Evaluation of the string test (Enterotest) for diagnosing Helicobacter pylori infection. Gastroenterology 1996; 110: A16.

30. Schneider RE, Torres M, Solis C, Passarelli L, Schneider FE, Vettorazzi $\mathrm{M}$. A simple method to detect Helicobacter pylori in gastric specimens. Br Med J 1990; 300: 1559.

31. Jiang C, Ferguson Jr DA, Chi DS, Li C, Ha T, Thomas E. A novel non-invasive consistently successful approach for the detection of gastric $\mathrm{H}$. pylori infection using the string test for culture, urease test and PCR. Gastroenterology 1997; 12: A161. 